Journal of Bangladesh Chemical Society, Vol. 25(2), 159-165, 2012

\title{
IMPACT OF HEAVY METALS ON WATER AND SOIL ENVIRONMENT OF A PAINT INDUSTRY
}

\author{
${ }^{\mathrm{a}}$ Y. N. JOLLY, ${ }^{\mathrm{b}}$ A. HOSSAIN, ${ }^{\mathrm{b}}$ A. SATTAR AND ${ }^{\mathrm{a} *}$ A. ISLAM \\ ${ }^{a}$ Chemistry Division, Atomic Energy Centre, P.O. Box 164, 4 Kazi Nazrul Islam Avenue, Dhaka- \\ 1000, Bangkadesh \\ ${ }^{b}$ Dept. of Chemistry and Chemical Technology, Islamic University, Kushtia, Bangladesh
}

\begin{abstract}
A study on the heavy metal impact of a paint industry effluent on the surrounding water and soil environment was carried out. This investigation included a variety of sample types essentially related to the impact assessment. The effluent samples collected from Berger Paints Bangladesh Ltd., Savar, were found to contain K, Ca, Mn, Fe, $\mathrm{Zn}$ and $\mathrm{Sr}$ with the mean concentrations of 9.78, 221, 0.027, 0.031, 0.067 and $0.29 \mathrm{mg} \mathrm{L}^{-1}$, and values of $\mathrm{pH}$, EC, TDS, TSS, BOD and COD measured in those samples were 5.8, 1.28 $\mathrm{mS} \mathrm{cm}{ }^{-1}, 1084 \mathrm{mgL}^{-1}, 66 \mathrm{mg} \mathrm{L}^{-1}$ and $101 \mathrm{mg} \mathrm{L}^{-1}$, respectively. The mean concentrations of $\mathrm{K}, \mathrm{Ca}, \mathrm{Mn}, \mathrm{Fe}, \mathrm{Zn}$ and $\mathrm{Sr}$ in groundwater samples and the values of $\mathrm{pH}, \mathrm{EC}$, TDS, TSS found in those samples were 1.58, 16.27, 0.25, 0.013, 0.058 and $0.14 \mathrm{mg} \mathrm{L}^{-1}$ and 7.2, $0.17 \mathrm{mS} \mathrm{cm}^{-1}, 145 \mathrm{mg} \mathrm{L}^{-1}$, and $10 \mathrm{mg} \mathrm{L}^{-1}$, respectively. The effluent receiving pond water showed the presence of $\mathrm{K}, \mathrm{Ca}, \mathrm{Fe}, \mathrm{Zn}, \mathrm{Br}$, and $\mathrm{Sr}$ with the average concentrations of $3.37,23,0.32,0.37,0.03$ and $0.11 \mathrm{mg} \mathrm{L}^{-1}$, respectively. The respective concentrations of elements-K, $\mathrm{Ca}, \mathrm{Mn}, \mathrm{Fe}, \mathrm{Cu}, \mathrm{Zn}, \mathrm{Br}, \mathrm{Rb}$ and $\mathrm{Sr}$ detected in aquatic plant (Halenchi shak) growing on effluent receiving pond water were 46400, 4846, 148, 174, 12.7, 62, 37, 124 and $23 \mathrm{mg} \mathrm{kg}^{-1}$. The mean contents of K, Ca, Ti, Mn, Fe, Cu, $\mathrm{Zn}, \mathrm{Rb}$ and $\mathrm{Sr}$ in samples of paint industry-adjacent agricultural land soil were 10128 , 8131,5260, 642, 24025, 56, 84, 135 and $138 \mathrm{mg} \mathrm{kg}^{-1}$, respectively. The mean concentrations of elements in pond water (K: 2.49, Ca: 15.2, Fe:0.19, Zn: 0.24, Br: 0.03 and Sr: $0.11 \mathrm{mgL}^{-1}$ ), Halenchi shak (K: 42259, Ca: <1837, Mn: <58, Fe: 163, Cu: $<14$, Zn: 47, Br: 20, Rb: 68 and Sr: $16 \mathrm{mg} \mathrm{kg}^{-1}$ ) and soil samples (K: <5491, Ca: <3300, Ti: 5034, Mn: 514, Fe: 34660, Cu: 58, Zn: 65, Rb: 135 and Sr: $38 \mathrm{mg} \mathrm{kg}^{-1}$ ) collected from a pollution free non-industrial zone indicated lower levels for the same parameters than those in corresponding above mentioned effluent-polluted samples.
\end{abstract}

\section{Introduction}

The paint industries all around the world have become the focus of attention of environment legislators as various types of hazardous and non-hazardous wastes are being discharged from these industries into our environment. The important environmental elements like soil, water and air are being continuously contaminated by toxic pollutants generated from these sources ${ }^{1}$. The types of effluents produced in the paint industries are liquid effluent, solid waste and volatile organic compounds. The paint industries in Bangladesh began in around 1953 in then East Pakistan. Now-a-days they have grown in different zones of the country. Because of the increasing demand of paints, these industries are still growing with time and have become a great threat to the

*Author for Correspondence; e-mail: ashraful.islam.aecd@gmail.com 
environment. Like other industries most of the paint industries have no wastewater treatment plant. Consequently the wastes of these industries are disposed into drains, canals and rivers without treatment and the solid wastes are dumped into surrounding land or water bodies which contaminate the soil or water with highly toxic inorganic or organic pollutants. The continuous receiving of waste water especially by water bodies poses a great threat to the aquatic life. The harmful inorganic and organic substances in the effluent degrade the normal characteristics of water by reducing the oxygen level and changing the composition of existing heavy metals and other organic constituents. As a result the usual life style of aquatic plants and animals are greatly hampered. The effects propagate through the food chain to affect human life. Paints, lacquers and varnishes are among the products that have distinct effects on environment and health.

The present work aims at studying the elemental levels in a paint industry effluent and their impact on the surrounding environmental components like effluent receiving pond water, the aquatic plant available on the effluent receiving pond and the effluent-affected agricultural land soil. The study also included the analyses of similar types of samples collected from a pollution free non-industrial zone for comparison.

\section{Experimental}

Sample collection

Berger Paints Bangladesh Ltd. located at Savar, Dhaka was selected for collection of effluent which, before disposal into the environment, undergoes treatment by neutralization process using lime and alum to facilitate the coagulation of suspended matter. The supernatant from the settling tank is subject to secondary treatment for subsequent settlement by aeration. The unused biomass is taken to the sludge drying beds and the liquid effluent is discharged into the environment ${ }^{2}$.

In order to study the effect of paint industry effluent on the environment, the samples including pond water into which effluent from the paint industry is directly discharged, groundwater used for washing paint waste, an aquatic plant (locally known as Halenchi shak) available on the effluent receiving pond and surface soil from paint industryadjacent agricultural land were collected. The samples of pond water, Halechi shak and the agricultural soil were also collected from a pollution free non-industrial zone far away from the paint industry under the present investigation. The liquid samples were collected in detergent-washed $1 \mathrm{~L}$ fresh polyethylene bottles and acidified ( $5 \mathrm{ml}$ per litre) with analar grade pure $\mathrm{HNO}_{3}$ just after collection. The effluent samples for BOD and COD determination were separately collected and not acidified. The electrical conductivity (EC) and $\mathrm{pH}$ of liquid samples were measured in the field before they were acidified. The solid samples were collected in fresh polyethylene bags. Each category of samples was collected by five folds. The samples were brought to the laboratory and preserved in a refrigerator until they were further processed. 


\section{Sample preparation}

\section{Liquid samples}

The samples including paint industry effluent, pond water and groundwater were filtered using Whatman 41 filter paper to remove any suspended solid particles. For heavy metal analysis using TXRF technique, $10 \mathrm{ml}$ of each type of sample taken in a plastic vial was further acidified with $0.5 \mathrm{ml}$ analar grade $\mathrm{HNO}_{3}$ and kept under action for 16 hours for complete dissolution of inorganic salt contained in smaller solid particles that might be present in the sample even after filtration. Then $3 \mathrm{ml}$ of the each type of sample was internally standardized with $6 \mu \mathrm{l}$ of commercially available standard yttrium solution (E. Merck, Germany).

\section{Solid Samples}

\section{Soil}

The samples were dried at $60^{\circ} \mathrm{C}$ in an oven overnight for complete removal of moisture, ground to fine power in an agate mortar with a pestle and preserved in polyethylene bags in a desiccator until analysis.

\section{Aquatic plant (Halenchi shak)}

The plant samples were first thoroughly washed with tap water and finally with deionized water and then dried in an oven at $60^{\circ} \mathrm{C}$ until constant weight was obtained. The dried samples were finally ground in a carbide mortar with a pestle and preserved in polyethylene bags in a desiccator until analysis.

\section{Methods of analysis}

Total Reflection X-ray Fluorescence (TXRF) and Isotopic Source-Excited Energy Dispersive X-ray Fluorescence (EDXRF) techniques were used for elemental analysis in liquid matrix ${ }^{3-4}$ and solid matrix ${ }^{4}$, respectively. For TXRF analysis a suitable volume of processed sample was standardized with an internal standard, yittrium (Y). The sample (6 $\mu \mathrm{l})$ was placed on an ultra-clean quartz reflector using an adjustable micro-pipette and dried under IR lamp at about $50^{\circ} \mathrm{C}$ for an hour and irradiated with totally reflected X-ray beam for 1000s for excitation of characteristic X-rays. In XRF analysis, $100.0 \mathrm{mg}$ powdered solid sample in the form of $1 \mathrm{~cm}$ diameter pellet was irradiated with Cd-109 radioisotope source for 4000s. In both methods the characteristic X-rays of the elements were detected by a Canberra $30 \mathrm{~mm}^{2} \mathrm{Si}(\mathrm{Li})$ detector (model SL 80175) with energy resolution of $170 \mathrm{eV}$ at $5.9 \mathrm{keV}$. The $\mathrm{X}$-ray spectra were collected on a Canberra Series 35 multi-channel analyzer (model 3210). The data processing and evaluation of X-ray spectra were carried out using a software programme called Analysis of X-ray Spectra by Iterative Least Square Fitting or $\mathrm{AXIL}^{5}$.

The other parameters including BOD, COD, soluble $\mathrm{N}$ and $\mathrm{P}$ in liquid samples were measured by adopting the standard methods ${ }^{6}$. 
Concentration calibration

For TXRF analysis of liquid samples, a calibration curve was constructed based on the Xray irradiation of triplicate multi-element standards prepared by mixing commercially available single element standards (E. Merck). The detailed calibration procedure is described elsewhere ${ }^{4}$. For XRF analysis of solid samples, the calibration curves were constructed based on reference materials namely soil-7 (IAEA CRM) for soil analysis and orchard leaf (NBS, SRM1571) for plant matrix analysis ${ }^{4}$.

\section{Results and discussion}

Physicochemical characteristics and trace element contents of paint industry effluent and groundwater

The effluent collected from Berger Paints Bangladesh Ltd. appeared to be clean with no detectable odor. As the effluent is nothing but groundwater washing waste, the heavy metal contribution of groundwater to the effluent was also checked. The results are shown in Table- 1 as an average of five fold measurements. For groundwater and effluent samples the average values of $\mathrm{pH}$ were 7.2 and 5.8 and those of EC were $0.17 \mathrm{mS} \mathrm{cm}^{-1}$ and $1.28 \mathrm{mS} \mathrm{cm}^{-1}$, respectively. The average BOD and COD values for the effluent were

Table 1. Physicochemical characteristics and trace metal concentrations in paint industry effluent and groundwater

\begin{tabular}{|c|c|c|c|c|c|c|c|c|c|c|}
\hline \multirow[t]{2}{*}{ Sample } & \multicolumn{10}{|c|}{ *Physicochemical properties, $\mathrm{mg} \mathrm{L}^{-1}$} \\
\hline & $\mathrm{pH}$ & \multicolumn{2}{|c|}{$\mathrm{EC}, \mathrm{mS} \mathrm{cm}^{-1}$} & TDS & TSS & BOD & \multicolumn{2}{|c|}{ COD } & Soluble N & Soluble P \\
\hline Effluent & $5.8 \pm 0.6$ & \multicolumn{2}{|c|}{$1.28 \pm 0.09$} & $1084 \pm 82$ & $16 \pm 2$ & $66 \pm 8$ & \multicolumn{2}{|c|}{$101 \pm 8$} & $15 \pm 0.22$ & $4.43 \pm 0.66$ \\
\hline Ground water & $7.2 \pm 0.5$ & \multicolumn{2}{|c|}{$0.17 \pm 0.01$} & $145 \pm 09$ & $10 \pm 2$ & - & \multicolumn{2}{|c|}{-} & $7.10 \pm 0.15$ & $4.16 \pm 0.58$ \\
\hline \multicolumn{11}{|c|}{ *Elemental concentration, $\mathrm{mg} \mathrm{L}^{-1}$} \\
\hline & \multicolumn{2}{|l|}{$\mathrm{K}$} & $\mathrm{Ca}$ & \multicolumn{2}{|c|}{$\mathrm{Mn}$} & \multicolumn{2}{|l|}{$\mathrm{Fe}$} & & $\mathrm{Zn}$ & $\mathrm{Sr}$ \\
\hline Effluent & \multicolumn{2}{|c|}{$9.78 \pm 1.47$} & $221 \pm 8.75$ & \multicolumn{2}{|c|}{$0.027 \pm 0.002$} & \multicolumn{2}{|c|}{$0.031 \pm 0.003$} & \multicolumn{2}{|c|}{$0.067 \pm 0.004$} & $0.29 \pm 0.04$ \\
\hline Ground water & \multicolumn{2}{|c|}{$1.58 \pm 0.24$} & $16.27 \pm 0.34$ & \multicolumn{2}{|c|}{$0.025 \pm 0.002$} & \multicolumn{2}{|c|}{$0.013 \pm 0.003$} & \multicolumn{2}{|c|}{$0.058 \pm 0.003$} & $0.14 \pm 0.01$ \\
\hline
\end{tabular}

* The results given in the Table indicate the mean of five fold measurements; The units where necessary was specifically defined for concerned parameter. .

found to be 66 and $101 \mathrm{mgL}^{-1}$, respectively. The ratio calculated from BOD and COD values of effluent was 0.66 showing that the effluent contained mostly biologically degradable substances ${ }^{7}$. TDS and TSS values for effluent were $1084 \mathrm{mg} \mathrm{L}^{-1}$ and $16 \mathrm{mg} \mathrm{L}^{-}$ ${ }^{1}$ and those for groundwater were 145 and $10 \mathrm{mg} \mathrm{L}^{-1}$, respectively. The values of $\mathrm{pH}$ and EC in effluent were higher than those in groundwater. The average concentrations of soluble $\mathrm{N}$ and $\mathrm{P}$ in the effluent were found to be $15 \mathrm{mg} \mathrm{L}^{-1}$ and $4.43 \mathrm{mg} \mathrm{L}^{-1}$, respectively which are higher than the groundwater values $\left(\mathrm{N}: 7.1 \mathrm{mg} \mathrm{L}^{-1} \mathrm{P}: 4.16 \mathrm{mg} \mathrm{L}^{-1}\right)$. The effluent samples have shown the presence of elements- $\mathrm{K}, \mathrm{Ca}, \mathrm{Mn}, \mathrm{Fe}, \mathrm{Zn}$, Sr having the average concentrations of $9.78,221,0.027,0.031,0.067,0.29 \mathrm{mgL}^{-1}$ and the average groundwater contents of these elements were 1.58, 16.27, 0.025, 0.013, 0.058, $0.14 \mathrm{mg} \mathrm{L}^{-1}$, 
respectively. Other elements- $\mathrm{V}, \mathrm{Cr}, \mathrm{Ni}, \mathrm{Cu}$, As in effluent and groundwater were found below the detection limits ( $\mathrm{V}:<0.9$, $\mathrm{Cr}:<0.07, \mathrm{Ni}:<0.02$, Cu: $<0.02$, As: $<0.01 \mathrm{mg} \mathrm{L}^{-1}$ ) . The element $\mathrm{Pb}$ could not be determined due to non-availability of the standard. From the Table- 1 it is observed that the average concentrations of the elements in the effluent samples are little higher than those in the groundwater which may be due to elemental contamination of groundwater from paint manufacturing raw materials while washing. The contents of $\mathrm{K}$ and $\mathrm{Ca}$ were found to be much higher than those in groundwater which are probably due to the contribution from the use of low-grade lime and alum for effluent treatment.

\section{Elemental concentration in pond water}

The polluted pond water collected from effluent receiving pond and the unpolluted pond water from pollution free non-industrial zone were analyzed for heavy metals (Table-2). The average concentrations of $\mathrm{K}, \mathrm{Ca}, \mathrm{Fe}, \mathrm{Zn}, \mathrm{Br}$, and $\mathrm{Sr}$ in polluted pond water and unpolluted pond water were 3.37, 23.0, 0.32, 0.37, 0.03, $0.12 \mathrm{mg} \mathrm{L}^{-1}$ and 2.49, 15.2, 0.19, $0.24,0.02,0.11 \mathrm{mg} \mathrm{L}^{-1}$, respectively indicating that the elemental concentrations in polluted pond water are little higher than those in the unpolluted pond water. The pollution of pond water with the effluent discharged into it is responsible for higher elemental levels.

Trace element concentrations of polluted and unpolluted aquatic plant (Halenchi shak)

Aquatic plant samples (Halenchi shak) collected from the effluent receiving pond were investigated for heavy metals and the results are shown in the Table-2. The mean contents of $\mathrm{K}, \mathrm{Ca}, \mathrm{Mn}, \mathrm{Fe}, \mathrm{Cu}, \mathrm{Zn}, \mathrm{Br}, \mathrm{Rb}, \mathrm{Sr}$ determined in these samples were 46400, 4846, $148,174,113,62,37,124,23 \mathrm{mg} \mathrm{kg}^{-1}$, respectively. The samples of the similar variety of plant samples collected from an unpolluted pond in the non-industrial zone were also analysed for heavy elements for comparison (Table-2). These samples showed the presence of $\mathrm{K}, \mathrm{Fe}, \mathrm{Zn}, \mathrm{Br}, \mathrm{Rb}$, and $\mathrm{Sr}$ having the average concentrations of 42259, 171, 51, 20, and 68, $16 \mathrm{mg} \mathrm{kg}^{-1}$, respectively. The concentrations of the elements in Halenchi shak from effluent receiving pond were found to be higher than those of the similar variety of plant samples from unpolluted pond. The higher results in the polluted plant might be due to the long term absorption of the elements by the plant from the paint industry effluent-mixed pond water. In case of Halenchi shak from the unpolluted pond the concentrations of $\mathrm{Ca}$ and $\mathrm{Mn}$ were found below their detection limits $\mathrm{Ca}:<1837 \mathrm{mg}$ $\mathrm{kg}^{-1}, \mathrm{Mn}:<58 \mathrm{mg} \mathrm{kg}^{-1}$ ). The reported concentrations of $\mathrm{K}, \mathrm{Fe}, \mathrm{Zn}, \mathrm{Rb}, \mathrm{Sr}$ in local green vegetables were found in the range of 2121-9887, 7.59- 72.6, 17.2- 196, 0.97-12.97 and 1.5- $50.1 \mathrm{mg} \mathrm{kg}^{-1}$, respectively, which are in good agreement with the present ones except $\mathrm{Rb}$ level which was high compared to the reported one ${ }^{8}$. The normal concentration ranges in plants reported for $\mathrm{Mn}, \mathrm{Cu}$ and $\mathrm{Zn}$ vary from 15-1000, 4-5, 8-400 $\mathrm{mg} \mathrm{kg}^{-1}$, respectively ${ }^{9}$. 
Table 2. Elemental concentrations in polluted samples collected from environment and unpolluted samples collected from non-industrial zone

industrial

\begin{tabular}{|c|c|c|c|c|c|c|}
\hline \multirow{2}{*}{ Elements } & *Concentration $\left(\mathrm{mg} \mathrm{L}^{-1}\right)$ & \multicolumn{3}{|c|}{ *Concentration $\left(\mathrm{mg} \mathrm{kg}^{-1}\right)$} \\
\cline { 2 - 7 } & \multicolumn{2}{|c|}{ Pond water } & \multicolumn{2}{c|}{ Halenchi shak } & \multicolumn{2}{c|}{ Agricultural soil } \\
\cline { 2 - 7 } & polluted & $\begin{array}{c}\text { unpollute } \\
\mathrm{d}\end{array}$ & polluted & unpolluted & polluted & $\begin{array}{c}\text { unpollute } \\
\mathrm{d}\end{array}$ \\
\hline $\mathrm{K}$ & $3.37 \pm .27$ & $2.49 \pm 0.27$ & $\begin{array}{c}46400 \pm 322 \\
5\end{array}$ & $\begin{array}{c}42259 \pm 440 \\
3\end{array}$ & $\begin{array}{c}10128 \pm 329 \\
0\end{array}$ & $<5491$ \\
\hline $\mathrm{Ca}$ & $22.99 \pm 0.37$ & $15.2 \pm 0.33$ & $4846 \pm 581$ & $<1837$ & $8131 \pm 2524$ & $<3300$ \\
\hline $\mathrm{Ti}$ & $<0.13$ & $<0.13$ & $<360$ & $<360$ & $5260 \pm 1395$ & $5034 \pm 133$ \\
& & & & & & 13 \\
\hline $\mathrm{V}$ & $<0.9$ & $<0.9$ & $<190$ & $<190$ & $<600$ & $<600$ \\
\hline $\mathrm{Cr}$ & $<0.07$ & $<0.07$ & $<95$ & $<95$ & $<335$ & $<335$ \\
\hline $\mathrm{Mn}$ & $<0.05$ & $<0.05$ & $148 \pm 21$ & $<58$ & $642 \pm 175$ & $514 \pm 155$ \\
\hline $\mathrm{Fe}$ & $0.32 \pm 0.03$ & $0.19 \pm 0.02$ & $174 \pm 26$ & $163 \pm 31$ & $24025 \pm 757$ & $34660 \pm 81$ \\
& & & & & 15 & 95 \\
\hline $\mathrm{Ni}$ & $<0.02$ & $<0.02$ & - & - & $48 \pm 23$ & $<45$ \\
\hline $\mathrm{Cu}$ & $<0.02$ & $<0.02$ & $12.7 \pm 3.3$ & $<14$ & $56 \pm 18$ & $58 \pm 27$ \\
\hline $\mathrm{Zn}$ & $0.37 \pm 0.02$ & $0.24 \pm 0.03$ & $62.0 \pm 5.4$ & $47 \pm 4.5$ & $84 \pm 23$ & $65 \pm 13$ \\
\hline $\mathrm{As}$ & $<0.01$ & $<0.01$ & $4.6 \pm 1.3$ & $<7.2$ & $<11.5$ & $<11.5$ \\
\hline $\mathrm{Br}$ & $0.03 \pm 0.01$ & $0.02 \pm 0.01$ & $37.0 \pm 2.7$ & $20 \pm 2$ & - & - \\
\hline $\mathrm{Rb}$ & $<0.05$ & $<0.05$ & $124 \pm+6$ & $68.0 \pm 3.8$ & $138 \pm 33$ & $135 \pm 33$ \\
\hline $\mathrm{Sr}$ & $0.11 \pm 0.02$ & $0.11 \pm 0.02$ & $23 \pm 2$ & $16.0 \pm 1.8$ & $138 \pm 33$ & $38 \pm 8$ \\
\hline
\end{tabular}

- The results given in the Table indicate the mean of five fold measurements

Elemental concentrations in polluted and unpolluted soil

The soil samples collected from the agricultural land close to the paint industry were analysed for heavy metals (Table-2). The mean concentrations of $\mathrm{Ca}$ :, $\mathrm{Ti}, \mathrm{Mn}, \mathrm{Fe}, \mathrm{Ni}, \mathrm{Cu}$, $\mathrm{Zn}, \mathrm{Rb}$ and $\mathrm{Sr}$ detected in the samples were 10128, 8131, 5260, 642, 24025, 48, 56, 84, 138 and138 $\mathrm{mg} \mathrm{kg}^{-1}$, respectively. Soil samples collected from a pollution free agricultural land were also investigated for heavy metals for a comparative study. The elements determined in the samples were $\mathrm{Ti}, \mathrm{Mn}, \mathrm{Fe}, \mathrm{Cu}, \mathrm{Zn}, \mathrm{Rb}$ and $\mathrm{Sr}$ having average concentrations of 5034, 514, 34660, 58, 65, 135, $38 \mathrm{mg} \mathrm{kg}^{-1}$, respectively (Table-2). Ca and $\mathrm{K}$ were detected below detection limits (K: $<5491 \mathrm{mg} \mathrm{kg}^{-1}$, Ca: $<3300 \mathrm{mg} \mathrm{kg}^{-1}$ ). The concentrations of the elements in polluted soil were found higher than those in the unpolluted soil indicating the heavy metal influence of the effluent discharged from the paint industry. The normal concentrations of heavy trace metals in agricultural soils are reported to vary from 200-2000, 10-1000, 2-100 and 10-300 mg kg ${ }^{-1}$ for $\mathrm{Mn}, \mathrm{Ni}$, Cu and Zn, respectively ${ }^{9}$. 


\section{Conclusion}

The paint industry effluent in terms of the elemental concentrations investigated did not seem to be so potential in polluting the environment. The heavy metal levels of the paint effluent-receiving pond water were found to be little higher than those in the samples collected from the pond having no linkage with any industry. The aquatic plant (Halenchi shak) collected from effluent receiving pond showed little higher elemental levels than the same variety of plant from non-polluted pond. In case of agricultural soil the concentrations of heavy metals in polluted soil were found little higher than those in unpolluted soil but still within with the normal. In view of the overall results obtained for heavy metals contents of the samples from the paint industry's environment and the non-industrial area the paint industry effluent did not seem to pose any serious threat to the environment.

\section{References}

1. P. M. Bhabani, Ph.D. Thesis, "Treatment of Waste Water Effluents Generated Due To the Use of Water-Based Paints for Removal of Toxic Metals and Organic Pollutants”, Jadavpur University, Calcutta, India, 1977.

2. Y. N. Jolly, Ph. D. Thesis, “Evaluation of Industrial Effluents for Irrigation”, University of Dhaka, 2011, p 123-125.

3. Wobrauschec and H. Alginger, J. Anal. Chem., 1975, 47(6), 852.

4. A. Islam and Y.N. Jolly, J. Bangladesh Aca. Sci., 2007, 31(2), 163-171.

5. P. Van Espan, H. Nullens and F. Adams, Nucl. Instr . and Meth., 142, 243, 1977.

6. J. T. Michael, in F. J. Welcher (Ed.), “Standard Methods of Chemical Analysis”, Robert E. Krieger Publishing Co. Inc., New York, U.S.A., 1975, p 2388-2439.

7. J. Toggyessy (Ed.), “Chemistry and Biology of Water, Air and Soil Environmental aspects”, Veda Publishing House of the Slovak Academy of Sciences, Bratislava, 1993, p. 224-232.

8. A. H. Khan, S.A. Tarafdar, M. Ali, S. K. Biswas, S. Akhter, D.K. Saha, M. Billah, S. A. Hadi and F. B. A. Maroof, J. Radanal. and Nucl. Chem., 1989, 134 (2), 367.

9. S. M. Ross (Ed.), “Toxic Metals in Soil-Plant Systems”, (1 $1^{\text {st }}$ edition), John Wiley \& Sons Ltd., England , 1994, p 9. 